\title{
Post-processing to remove residual clouds from aerosol optical depth retrieved using the Advanced Along Track Scanning Radiometer
}

\author{
Larisa Sogacheva $^{1}$, Pekka Kolmonen ${ }^{1}$, Timo H. Virtanen ${ }^{1}$, Edith Rodriguez ${ }^{1}$, Giulia Saponaro ${ }^{1}$, and \\ Gerrit de Leeuw ${ }^{1,2}$ \\ ${ }^{1}$ Climate Research, Finnish Meteorological Institute, Helsinki, 00560, Finland \\ ${ }^{2}$ Department of Physics, University of Helsinki, Helsinki, 00560, Finland \\ Correspondence to: Larisa Sogacheva (larisa.sogacheva@fmi.fi)
}

Received: 31 March 2016 - Discussion started: 6 July 2016

Revised: 14 December 2016 - Accepted: 3 January 2017 - Published: 13 February 2017

\begin{abstract}
Cloud misclassification is a serious problem in the retrieval of aerosol optical depth (AOD), which might considerably bias the AOD results. On the one hand, residual cloud contamination leads to AOD overestimation, whereas the removal of high-AOD pixels (due to their misclassification as clouds) leads to underestimation. To remove cloudcontaminated areas in AOD retrieved from reflectances measured with the (Advanced) Along Track Scanning Radiometers (ATSR-2 and AATSR), using the ATSR dual-view algorithm (ADV) over land or the ATSR single-view algorithm (ASV) over ocean, a cloud post-processing (CPP) scheme has been developed at the Finnish Meteorological Institute (FMI) as described in Kolmonen et al. (2016). The application of this scheme results in the removal of cloudcontaminated areas, providing spatially smoother AOD maps and favourable comparison with AOD obtained from the ground-based reference measurements from the AERONET sun photometer network. However, closer inspection shows that the CPP also removes areas with elevated AOD not due to cloud contamination, as shown in this paper. We present an improved CPP scheme which better discriminates between cloud-free and cloud-contaminated areas. The CPP thresholds have been further evaluated and adjusted according to the findings. The thresholds for the detection of high-AOD regions ( $>60 \%$ of the retrieved pixels should be high-AOD $(>0.6)$ pixels), and cloud contamination criteria for lowAOD regions have been accepted as the default for AOD global post-processing in the improved CPP. Retaining elevated AOD while effectively removing cloud-contaminated pixels affects the resulting global and regional mean AOD values as well as coverage. Effects of the CPP scheme on
\end{abstract}

both spatial and temporal variation for the period 2002-2012 are discussed. With the improved CPP, the AOD coverage increases by $10-15 \%$ with respect to the existing scheme. The validation versus AERONET shows an improvement of the correlation coefficient from 0.84 to 0.86 for the global data set for the period 2002-2012. The global aggregated AOD over land for the period 2003-2011 is 0.163 with the improved CPP compared to 0.144 with the existing scheme. The aggregated AOD over ocean and globally (land and ocean together) is 0.164 with the improved CPP scheme (compared to 0.152 and 0.150 with the existing scheme, for ocean and globally respectively). Effects of the improved CPP scheme on the 10-year time series are illustrated and seasonal and temporal changes are discussed. The improved CPP method introduced here is applicable to other aerosol retrieval algorithms. However, the thresholds for detecting the high-AOD regions, which were developed for AATSR, might have to be adjusted to the actual features of the instruments.

\section{Introduction}

The retrieval of aerosol properties from radiance measured at the top of the atmosphere (TOA) using space-borne instruments is highly sensitive to the presence of clouds. Aerosol retrieval is only performed for cloud-free areas, which implies that a very strict cloud detection scheme has to be applied to remove all cloud-contaminated pixels from the retrieval area. If pixels in the retrieval area contain undetected clouds, the aerosol optical depth (AOD) will be too high, while, if the cloud detection is too strict, i.e. pixels 
are removed which do not contain clouds, aerosol pixels are wrongly discarded. Thus, effective cloud screening for aerosol retrieval is important and requires sophisticated algorithms and multispectral visible and infrared radiance data (e.g. Remer et al., 2005; Frey et al., 2008; Grandey et al., 2013; Backer, 2013; Shi et al., 2014).

No perfect method for cloud detection in satellite data exists and cloud contamination is considered one of the major problems in aerosol retrieval results. Cloud contamination imposes a positive but unknown bias in the AOD values which may vary with time and thus hamper the use of these data for trend analysis and other studies. Shi et al. (2014) showed that, on average, thin cirrus cloud contamination introduces a possible $\sim 0.01$ high bias in the AOD at $0.558 \mu \mathrm{m}$ wavelength retrieved over water using MISR (Multi-angle Imaging SpectroRadiometer) data. Over the midlatitude to high-latitude oceans and south-east Asia, this number increases to 0.015-0.02. For MODIS, Kaufman et al. (2005) showed that residual cirrus clouds result in an AOD at $0.55 \mu \mathrm{m}$, which is high by $0.015 \pm 0.003$. Zhang et al. (2005) showed that cloud contamination results in an overestimation of $10-20 \%$ in the monthly mean AOD or in the aerosol direct radiative effect over oceans. Zhao et al. (2013) found that cloud contamination imposes not only a positive bias on AOD values but also a positive bias on its long-term trend.

Cloud misclassification occurs because of the large variety in cloud and underlying surface properties. It comes from, e.g. the thin cloud pixels (underestimation over dark surfaces, overestimation over a high albedo surface), small cumulus pixels, clear pixels over bright surface (e.g. Wang et al., 2013). Optically dense aerosol features, such as desert dust plumes, volcanic ash, biomass burning aerosol and industrial pollution, can be misidentified as clouds (Martins et al., 2002; Kahn et al., 2007; Stap et al., 2015).

To eliminate residual clouds from the retrieved AOD fields, a cloud post-processing method has been developed to recognise and discard undetected clouds in AOD retrieved from the AATSR radiances with the ATSR dualview (ADV) algorithm for aerosol retrieval over land and the ATSR single-view (ASV) aerosol retrieval algorithm for application over ocean (Kolmonen et al., 2016). The ATSR has been designed to measure sea surface temperature and, therefore, the cloud detection scheme designed for use with this instrument has been optimised for application over open ocean and does not perform well over land (Závody et al., 2000; Birks, 2007a). Therefore, an improved cloud detection scheme has been developed for application to ADV/ASV (Roblez González, 2003; Kolmonen et al., 2016), but the retrieved AOD is still affected by residual cloud contamination. To remove this, a cloud post-processing (CPP) algorithm has been designed at the Finnish Meteorological Institute (FMI) which partially solves the problem, as illustrated by Kolmonen et al. (2016), and results in smoother AOD maps and improved validation results when compared to AOD data from the AERONET, which is a federated net- work of sun photometer instruments (Holben et al., 1998). Based on the CPP test, if a certain retrieved pixel is found to be cloud-contaminated, as recognised from the AOD spatial distribution, no retrieval products are provided for that pixel. However, as shown in this paper, it also appears that areas with elevated AOD may inadvertently be removed by the existing CPP method (Kolmonen et al., 2016), resulting in screening of high-AOD events. To avoid this, a method has been developed to detect high-AOD regions and prevent their elimination from the retrieval results, while still effectively removing cloud-contaminated pixels as in the existing CCP scheme. This method is applicable to other aerosol retrieval algorithms. However, the thresholds for detecting the high-AOD regions, which were developed for AATSR, might have to be adapted to the actual features of instruments (e.g. width of the swath).

The paper is structured as follows. The most important features of the AATSR instrument, the ADV/ASV retrieval algorithms and the ADV/ASV cloud tests are described in Sect. 2.1. Cloud-screening results and retrieved AOD are illustrated with some examples in Sect. 2.2. Post-processing methods, both the existing and the improved versions, are described in Sect. 3. Test results are illustrated with examples (Sect. 4.1). The AOD results are evaluated in Sect. 4.2. The effects of the two schemes are discussed in Sect. 4.3 as regards the effects of the improved CPP on the spatial AOD distributions globally and over eastern China. Time series over different regions for 2002-2012 are presented in Sect. 4.4. The conclusions are summarised in Sect. 5.

\section{The ADV/ASV aerosol retrieval algorithm}

\subsection{Methods}

The ATSR dual-view (ADV) algorithm has been developed for the ATSR instruments (ATSR-2 on board ERS-2, 19952003, and AATSR on board ENVISAT, 2002-2012) for the retrieval of aerosol properties. The ATSRs are dual-view instruments, with one view near-nadir and the other one at a $55^{\circ}$ forward angle. They have a conical scan mechanism with a swath width of $512 \mathrm{~km}$, which results in global coverage in 5-6 days. ATSRs measures the TOA upwelling radiation in seven wave bands, three in the visible - near infrared (centred near $0.555,0.659,0.865 \mu \mathrm{m})$ and four in the near-to-thermal infrared (centred near 1.61, 3.7, 10.85, $12 \mu \mathrm{m}$ ). The nominal resolution at nadir is $1 \times 1 \mathrm{~km}^{2}$. ATSRs flew in a sun synchronous orbit in a descending mode with a local equator crossing time at 10:30.

Over land, the ADV uses the two ATSR views simultaneously to eliminate the contribution of land surface reflectance to the TOA radiation (Veefkind et al., 1998; Kolmonen et al., 2016). AOD retrieval is based on the assumption that the ratio of the surface reflectance for the nadir and forward ATSR view ( $k$ ratio) is independent of wavelength (Flowerdew and 


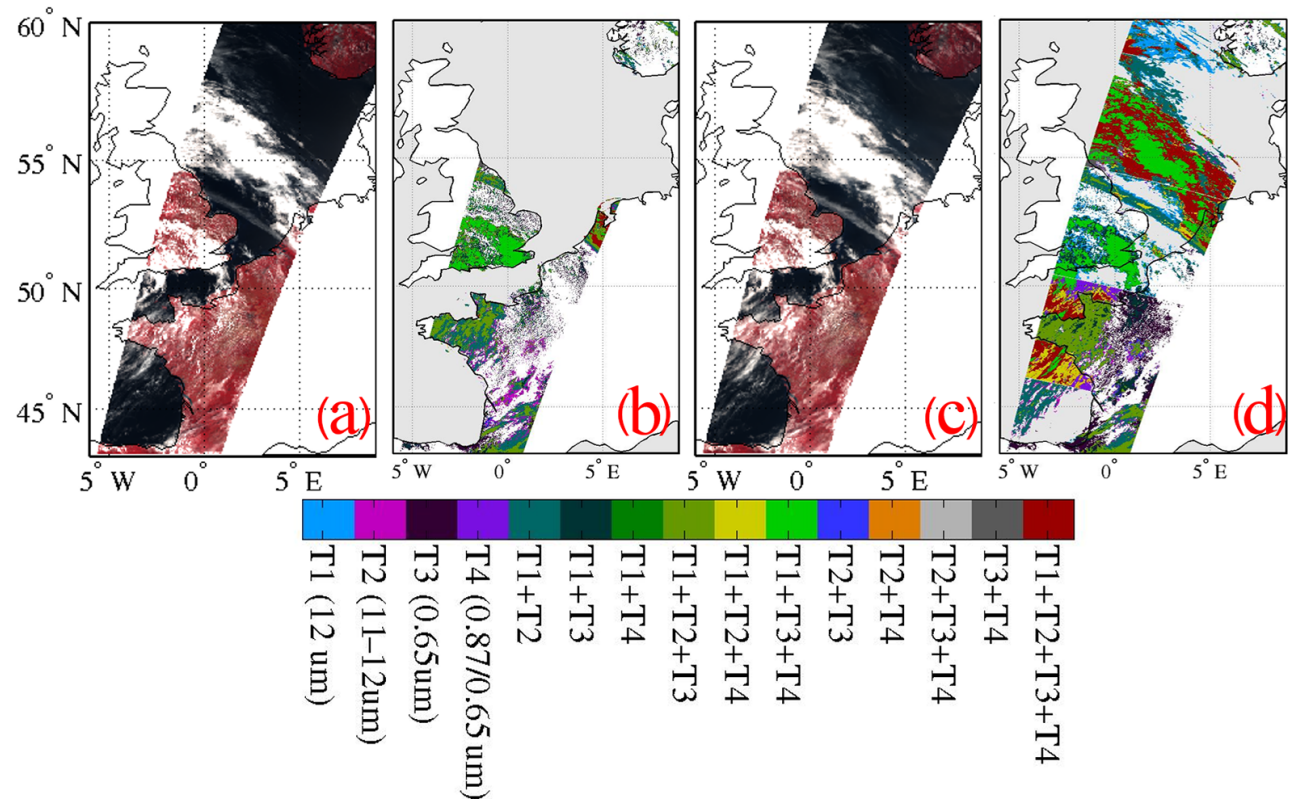

Figure 1. False-colour RGB images (composite of $0.555,0.659$ and $0.865 \mu \mathrm{m}$ ) from the AATSR nadir (a) and forward (c) views over part of western Europe on 29 July 2008, 10:00 UTC. Along the track, vegetation over land is coloured in red, ocean is coloured in black, and clouds are coloured in white. Dark areas are cloud free. Cloud-screening test T1-T4 results are presented for nadir (b) and forward (d) views with colours indicating the (combination of) tests (colour bar at the bottom). See Sects. 2.2 and 3 for further explanation.

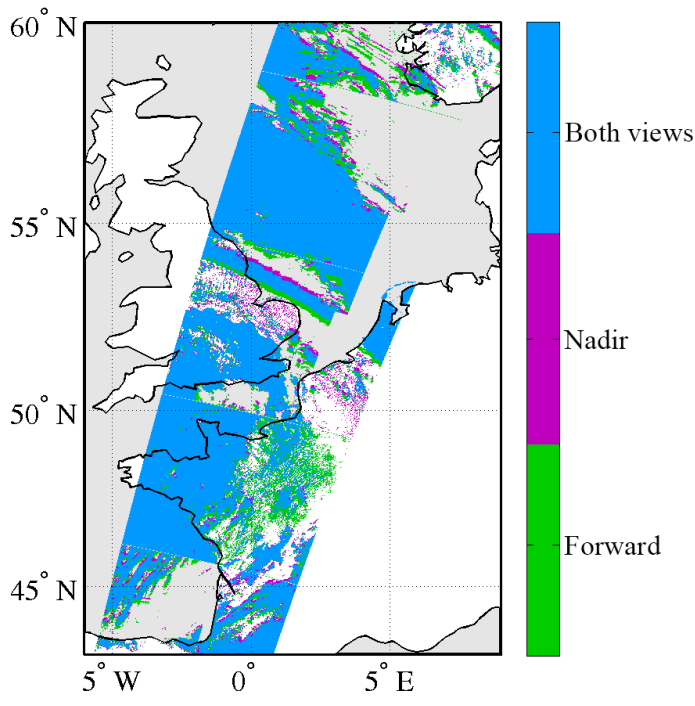

Figure 2. Stereo view effect in nadir/forward cloud screening, for the overpass on 29 July 2008, ca. 10:00 UTC (as in Fig. 1). Clouds detected with at least one of four tests in both views, in only nadir and in only forward views are coloured with light blue, magenta and green respectively. To better show the stereo effect, cloud screening over ocean was performed here for both nadir and forward views.

Haigh, 1995). The current $k$ ratio assumption is not reliable over bright surfaces, such as deserts and snow (Kolmonen et al., 2016), thus aerosol retrievals over bright surfaces are not performed. The ATSR single-view (ASV) algorithm for the retrieval of aerosol properties over water uses a model for the ocean surface reflectance, which is subtracted from the measured TOA reflectance to retain the path radiance (Veefkind and de Leeuw, 1998). The differences between the measured and modelled TOA reflectances are simultaneously minimised at all four (over ocean) or three (over land, where for the $0.865 \mu \mathrm{m}$ wave band the $k$ ratio assumption does not hold) wavelengths. For the land/ocean and glint over ocean detection, the AATSR flags are used. The current status of the ATSR ADV/ASV aerosol retrieval algorithm is described in Kolmonen et al. (2016). The AOD retrieval is performed in cloud-free and glint-free areas.

Cloud detection in ADV/ASV is done with the AATSR Level $1 \mathrm{~B}$ pixels with a nominal resolution of $1 \times 1 \mathrm{~km}^{2}$ at nadir. The AATSR ESA standard cloud mask (Birks, 2007b) is not used in the ADV/ASV. Plummer (2008) demonstrated the standard mask tendency to falsely flag clear-sky pixels as cloud. Therefore, a set of four different tests to detect the presence of clouds in each pixel is applied in ADV/ASV:

- gross cloud test (T1)

- thin cirrus test (T2)

- TOA reflectance test (T3)

- reflectance ratio test (T4).

The gross cloud (T1) and thin cirrus (T2) tests are similar to the AATSR ESA standard cloud tests six and seven 

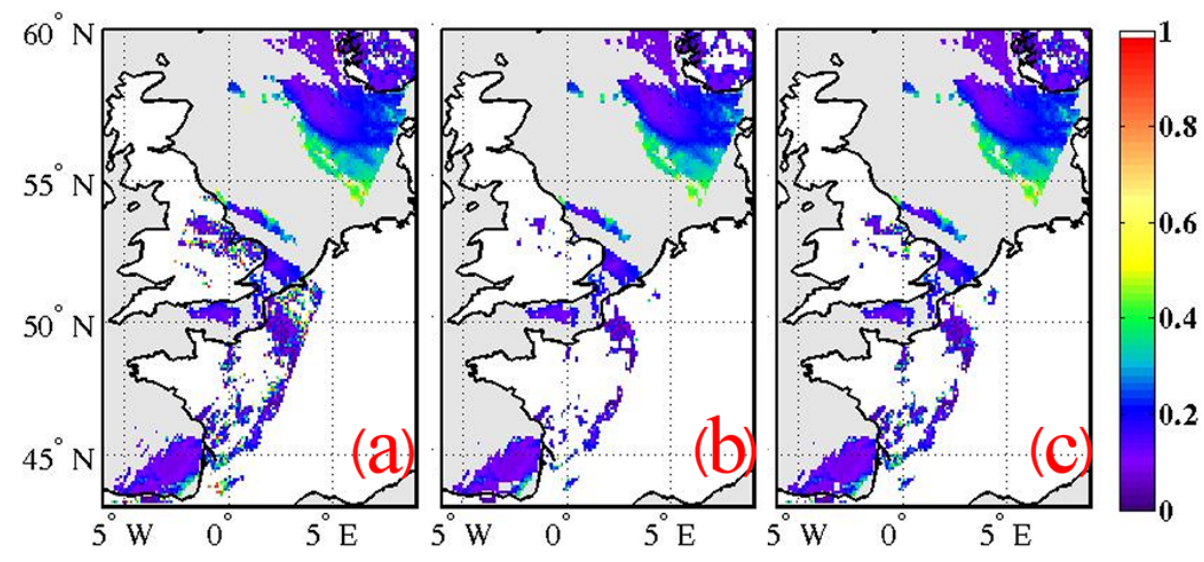

Figure 3. Example of a retrieval scene over western Europe, for the overpass on 29 July 2008, ca. 10:00 UTC (as in Fig. 1): all L2 AOD pixels retrieved (a), after the application of the initial cloud post-processing method discussed in Sect. 3.1 (b) and after the application of the improved post-processing discussed in Sect. 3.2 (c).

(Birks, 2007b). ADV/ASV TOA reflectance (T3) and reflectance ratio (T4) tests are based on the work by Koelemeijer et al. (2001) and Robles González (2003). Robles González (2003) also developed a method to automate the cloud-screening process. To this end, the AATSR orbits are divided into scenes of $512 \times 480$ pixels and for each scene histograms of the brightness temperatures or reflectances are created and used to automatically determine thresholds or rejection values for tests T1, T3 and T4. All tests are performed independently. Over land, where both the nadir and forward AATSR views are used in ADV, cloud tests are applied to both views. Over ocean, where only the forward view is used in ASV, cloud tests are applied to the forward view only. If at least one of four (over ocean, eight over land) tests recognises clouds, then that pixel is considered cloudy and discarded from the AOD retrieval. The validation of the AOD results and visual inspection of the AOD spatial distribution are the main approaches for the evaluation of cloud-screening results.

The default retrieval is performed on retrieval areas of $0.1^{\circ} \times 0.1^{\circ}$. The results are regridded to a $10 \times 10 \mathrm{~km}^{2}$ sinusoidal grid (L2) and a $1^{\circ} \times 1^{\circ}$ (L3) grid. Note that by globally or regionally averaged AOD we mean AOD aggregated over the retrieved pixels, excluding glint, cloud-contaminated areas and other areas or conditions (e.g. deserts, snow), where $\mathrm{AOD}$ is not retrieved because of the limitations in ADV/ASV.

\subsection{Cloud-screening results}

Figure 1 shows the false-colour RGB images (composite of $0.555,0.659$ and $0.865 \mu \mathrm{m}$ ) for the AATSR nadir (a) and forward (c) views over part of western Europe. Results from the application of the various cloud tests are shown in Fig. 1b (nadir, over land only) and Fig. 1d (forward). The results for the different tests and combinations of them are coded as indicated in the colour bar below the figures. Over land (southern UK, France), the gross cloud test (T1), the brightness temperature difference test (T2) and the reflectance ratio test (T4) show similar results for both views, whereas the reflectance test (T3) recognises more clouds in the forward view. A thick stratus cloud over the North Sea is recognised by all four tests in the forward view (nadir is not used in over ocean retrieval). To the south of that thick cloud, a cirrus cloud is clearly recognised in both views. Thin cirrus clouds are discarded by tests T1, T2 and T4 over the North Atlantic.

The cloud-screening results are not smooth, since the cloud tests are applied to scenes of $512 \times 4801 \mathrm{~km}$ resolution pixels areas. The discontinuity in the cloud test results in Fig. $1 \mathrm{~d}\left(\mathrm{ca} .46\right.$ and $50^{\circ} \mathrm{N}$ ) is explained by the fact that for each separate scene thresholds are chosen automatically and may differ from neighbouring areas. However, since in most cases a cloud area is detected with several tests and a pixel is considered cloudy if at least one test indicates the presence of clouds, such disagreement in thresholds does not have a major influence on the final decision of whether a pixel is cloudy or cloud-free.

For the imagery provided by a dual-view instrument one should remember the so-called stereo effects (Virtanen et al., 2014) which often occur at cloud edges. In (A)ATSR Level $1 \mathrm{~B}$ data the forward and nadir views are nominally collocated at a standard surface ellipsoid corresponding to sea level. In the case of a cloud located above a given surface pixel, the forward view might look under the cloud when approaching the cloud edge, while the nadir view sees a fully cloud pixel. These effects on cloud screening are illustrated in Fig. 2, where the cloud detection by the forward, the nadir, and both views are indicated in colour. The stereo effect is clearly visible at the edges of the cloud over the North Sea, e.g. between 53 and $55^{\circ} \mathrm{N}$ where the red area indicates that the cloud edge is detected by the nadir view but not yet by the forward view (AATSR flies in descending mode, i.e. from north to south). Taking into account the AATSR geometry, 

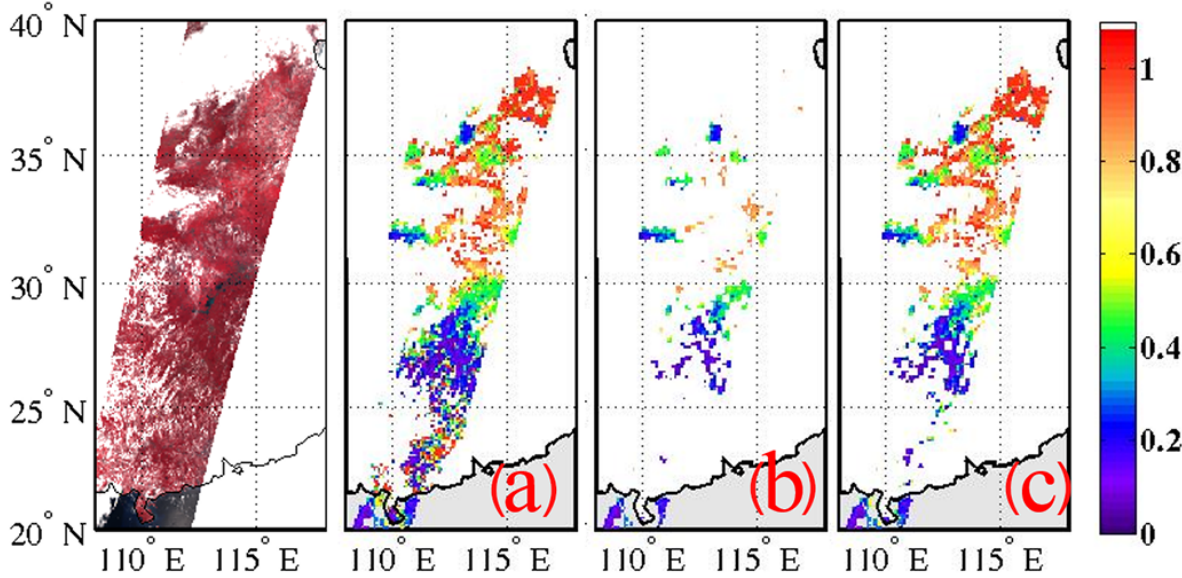

Figure 4. Example of a retrieval scene over China, for the overpass on 18 August 2010: false-colour RGB image for nadir view (left), L2 AOD retrieved with ADV/ASV (a), after the application of ExCPP (b) and after the application of the ImCPP (c) described in Sect. 3.2.
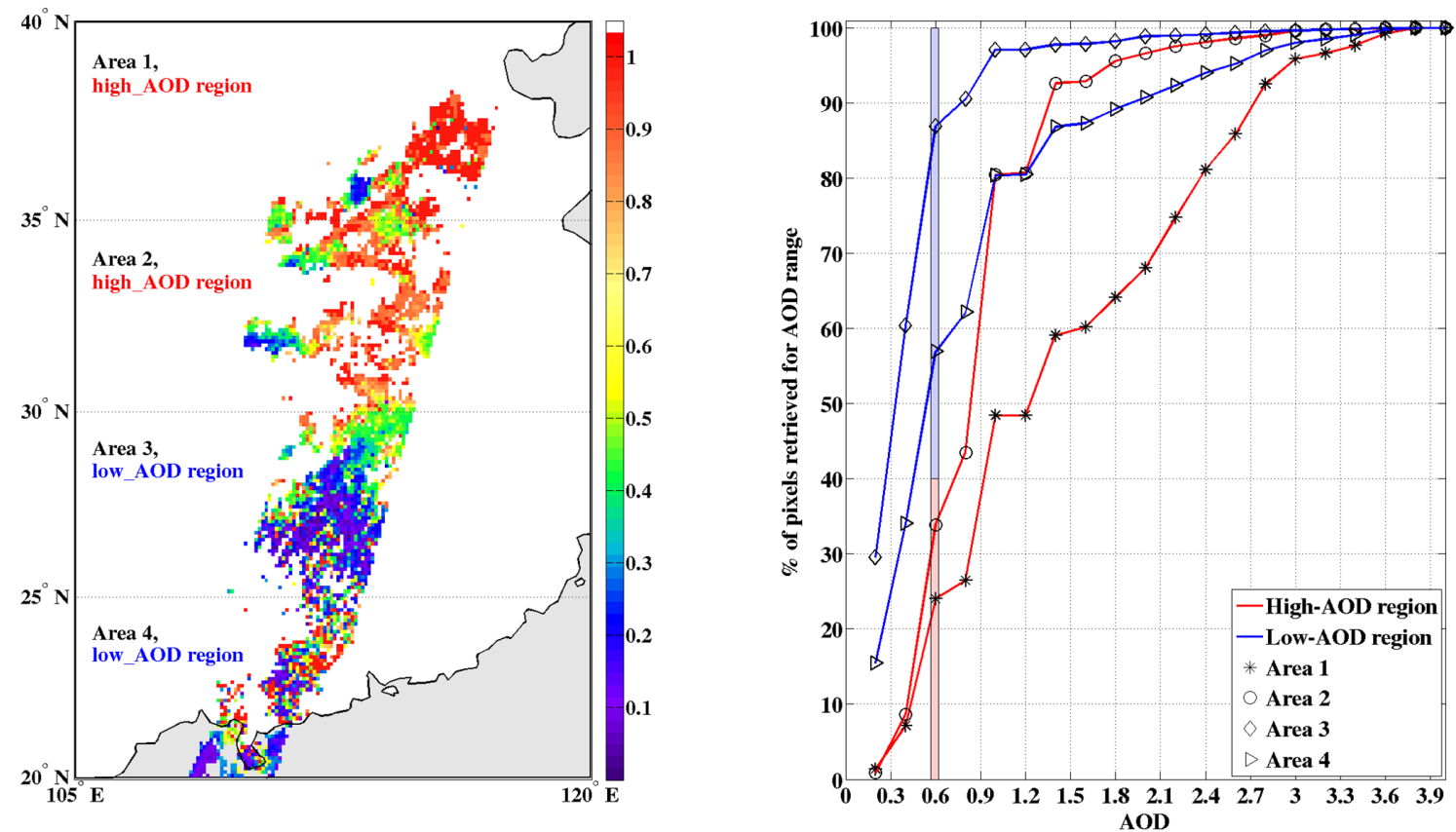

Figure 5. Example of a retrieval scene over China, for the overpass on 18 August 2010, 01:00 UTC: all L2 AOD pixels, the subdivision of the partial track in $5^{\circ}$ test areas is illustrated (a), high-AOD regions classification results: cumulative percentage of pixels retrieved for AOD ranges in test areas $1-4(\mathbf{b})$.

the nadir-retrieved cloud footprint is slightly (up to five pixels) shifted, compared with the forward view, to the north and east, depending on the cloud shape and height. Therefore, since both nadir and forward views are used in ADV over land, the pixel in ADV AOD retrieval should be cloudfree for aerosol retrieval in both views to avoid any possible cloud contamination.

The AOD retrieved with ADV/ASV for cloud-free pixels (as recognised with the four ADV/ASV cloud tests) for the same test scene used in Figs. 1 and 2 is shown in Fig. 3.
Most of the retrieved pixels show AOD values of $0.1-0.4$ (Fig. 3a). However, near cloud edges or over areas with scattered clouds, such as over parts of the UK and France, some clouds are missed by the ADV/ASV cloud tests, resulting in cloud-contaminated retrieval areas where the AOD is unreasonably high compared with the surrounding areas. As a result, the application of the retrieved AOD for climate or air quality studies over such areas would yield overestimated values. To avoid cloud contamination due to residual clouds, CPP method has been developed as explained in Sect. 3. 

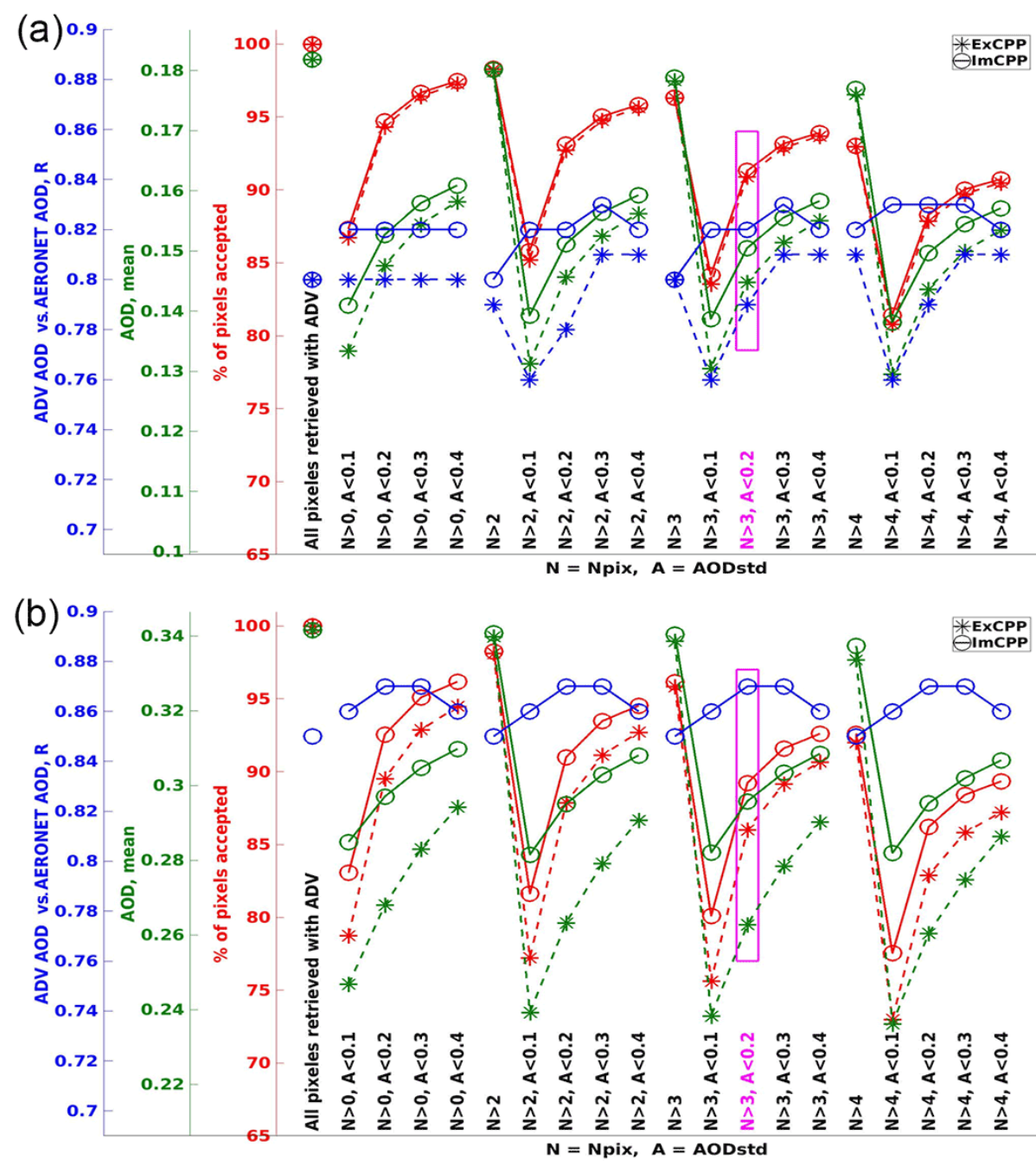

Figure 6. ADV AOD vs. AERONET AOD validation results (blue, $R$ correlation coefficient), AOD yearly means (green), percentage of the pixels accepted from number of all pixels retrieved with ADV (red) for different combinations of Npix $(N)$ and AODstd $(A)$ thresholds ( $x$ axis) for ExCPP (dashed lines) and ImCPP (solid lines) globally (a) and over China (b) for 2010. The magenta rectangle shows the thresholds selected for ImCPP (based on the combination of better validation results, better coverage and visual inspection, see Sect. 3.2.2 for a more detailed explanation). Note: different scale for AOD mean; for the ExCPP, there are no validation points over China.

\section{Cloud post-processing}

\subsection{Existing post-processing method and limitation}

A cloud post-processing method has been developed for application to L2 AOD data $\left(0.555 \mu \mathrm{m}, 0.1^{\circ} \times 0.1^{\circ}\right.$ resolution) to filter out retrieval areas which are potentially cloudcontaminated, i.e. include residual clouds not detected by the initial cloud screening (Kolmonen et al., 2016). The existing CPP (ExCPP) method includes two tests to determine whether a L2 pixel (referred to as a pixel hereafter) might be cloud contaminated. Each pixel is analysed with eight surrounding pixels (or less, at the edges of the orbit or scene). The first check determines the number of pixels retrieved in this test area (Npix). If, together with the tested pixel, less than four pixels are retrieved in the area, the tested pixel is considered to be potentially cloud contaminated and is discarded from the results. If the tested pixel passes the first test, the homogeneity of the AOD (AODstd) in the 9-pixel area is checked: if the AOD standard deviation is larger than 0.1 , the tested pixel is discarded. The value of the standard deviation 0.1 was chosen as a compromise between global coverage and acceptable validation results.

An example of the application of this CPP method for the test scene over western Europe is presented in Fig. 3b. The method recognises AOD areas with high AOD due to cloud contamination over the UK and France (Fig. 3a) and discards them (Fig. 3b). However, when applied over areas with higher AOD the method may also remove areas which are not cloud contaminated, as illustrated for eastern China (Fig. 4). 
Table 1. Number of pixels left (compared to number of ADV/ASV-retrieved pixels) after the application of the existing CPP and the improved CPP for different cases, see Fig. 7. For orbit details, in ATS_TOA_1PUUPAyyyymmdd_hhmiss_000065272091_00403_nnnnn_7095.N1, yyyy is year, mm is month, $d$ is day, $h$ is hour, min is minute, $s$ is seconds, nnnnn is the ENVISAT orbit number.

\begin{tabular}{lrrr}
\hline Case description, AATSR orbit details & $\begin{array}{r}\text { Area } \\
\text { of interest }\end{array}$ & $\begin{array}{r}\text { Pixels left } \\
\text { ExCPP, } \%\end{array}$ & $\begin{array}{r}\text { Pixels left } \\
\text { ImCPP, } \%\end{array}$ \\
\hline Case 1, anthropogenic pollution & $\begin{array}{r}25-40^{\circ} \mathrm{N}, \\
115-125^{\circ} \mathrm{E} \\
25-40^{\circ} \mathrm{N},\end{array}$ & 71.6 & 93.4 \\
ATS_TOA_1PUUPA20100803_013811_000065272091_00403_44044_7095.N1 & 55.8 & 89.5 \\
Case 2, anthropogenic pollution & $\begin{array}{r}110-120^{\circ} \mathrm{E} \\
15-25^{\circ} \mathrm{N},\end{array}$ & 76.9 & 82.3 \\
ATS_TOA_1PUUPA20110724_015743_000065273104_00419_49140_3111.N1 & $30-40^{\circ} \mathrm{W}$ & & \\
Case 3, Saharan dust & $50-65^{\circ} \mathrm{N}$, & 91.6 & 96.1 \\
ATS_TOA_1PUUPA20060312_090349_000065272045_00479_21074_4641.N1 & $55-70^{\circ} \mathrm{E}$ & & \\
Case 4, biomass burning & & \\
ATS_TOA_1PUUPA20100801_060236_000065272091_00377_44018_7901.N1 & & \\
\hline
\end{tabular}

(a)

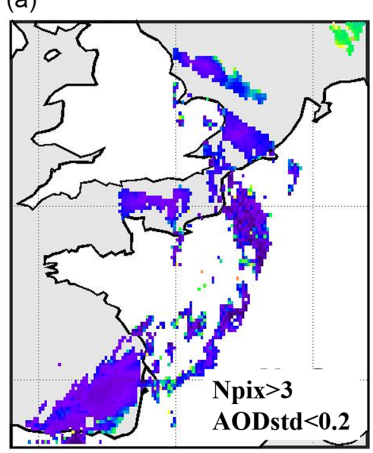

(b)

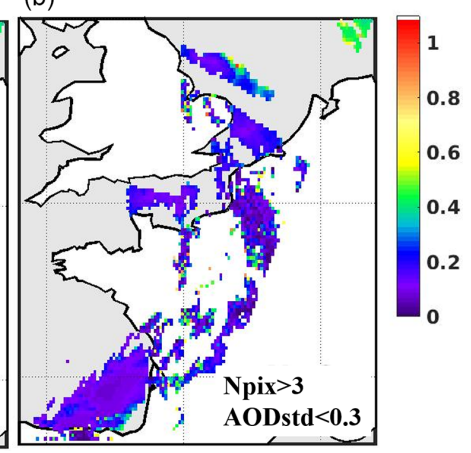

Figure 7. Example of the visual inspection of the AOD spatial distribution for the overpass on 29th July 2008, ca. 10:00 UTC (as in Figs. 1-3) for AODstd $<0.2$ (a) and AODstd $<0.3$ (b).

The false-colour RGB image for the nadir view (Fig. 4, left) shows that most of the AATSR track is cloud-free over that area. Figure 4a shows the AOD retrieved using ADV/ASV before application of the ExCPP method. Figure 4b shows that the cloud-contaminated pixels south of $25^{\circ} \mathrm{N}$ are effectively removed by the ExCPP method as it was designed for. The area with high AOD (up to 1) north of $30^{\circ} \mathrm{N}$ is clearly visible (Fig. 4a) but after ExCPP it has been almost completely removed (Fig. 4b). Similar problems occur during high-AOD episodes, such as biomass burning in Africa or Saharan dust outbreaks over the North Atlantic (see Fig. 7 and further discussion in Sect. 4).

Globally, with this existing CPP method, about $15 \%$ of the pixels are discarded as possibly cloud-contaminated. Validation of the remaining AOD with AERONET data (see Sect. 4.2 for more details about the AERONET) shows the improvement of the ADV-retrieved AOD with respect to those before CPP, i.e. the correlation coefficient before CPP is $R=0.80$ compared to $R=0.84$ after CPP (see Fig. 8, upper panel). However, the inadvertent removal of areas with high AOD is not satisfactory. Below we describe the im- provement of the existing CPP to avoid removal of highAOD episodes.

\subsection{Improved post-processing method and limitation}

\subsubsection{Detection of high-AOD regions}

The reason the ExCPP method fails for high-AOD regions is that in those areas the AOD spatial variation in the $3 \times 3$ pixel areas is much higher than the limiting value of 0.1 . This limit works well in low-AOD conditions, but in high-AOD conditions it appears to be too strict. Thus, an improved CPP (ImCPP) method to recognise high-AOD regions needed to be developed to avoid the inadvertent removal of high-AOD values.

The test for recognising high-AOD regions is applied to parts of AATSR tracks extending $5^{\circ}$ in latitude, which is consistent with the size of the scenes in the ADV/ASV cloud detection procedure, as illustrated in Fig. 5a. This size was chosen by visual inspection, taking into account the AATSR track width and spatial extent of high-AOD areas where the existing CPP method fails. Five years of AATSR ADV/ASV AOD data have been visually inspected and about 150 highAOD cases were chosen for testing, including e.g. anthropogenic pollution over China, biomass burning and dust outbreaks. Each test case covered 3-4 test areas of $5^{\circ}$ in latitude, which resulted in ca. 500 test areas in total. For each of these areas, a cumulative AOD distribution function was calculated as illustrated in Fig. 5b to determine whether the area was a high-AOD or a low-AOD area. To this end, as a result of the cumulative AOD distribution functions analysis, the AOD value of 0.6 was empirically determined as the first criteria for high-AOD region detection. Next, the sizes of the low $(<0.6)$ and high-AOD $(>0.6)$ areas were estimated and the threshold for the fraction of low-AOD pixels was determined. If the percentage of the AOD pixels in the area with AOD values below 0.6 is larger than $40 \%$ the area is considered a low-AOD area, and Npix and AODstd tests are applied as discussed above. High-AOD regions are defined as areas 

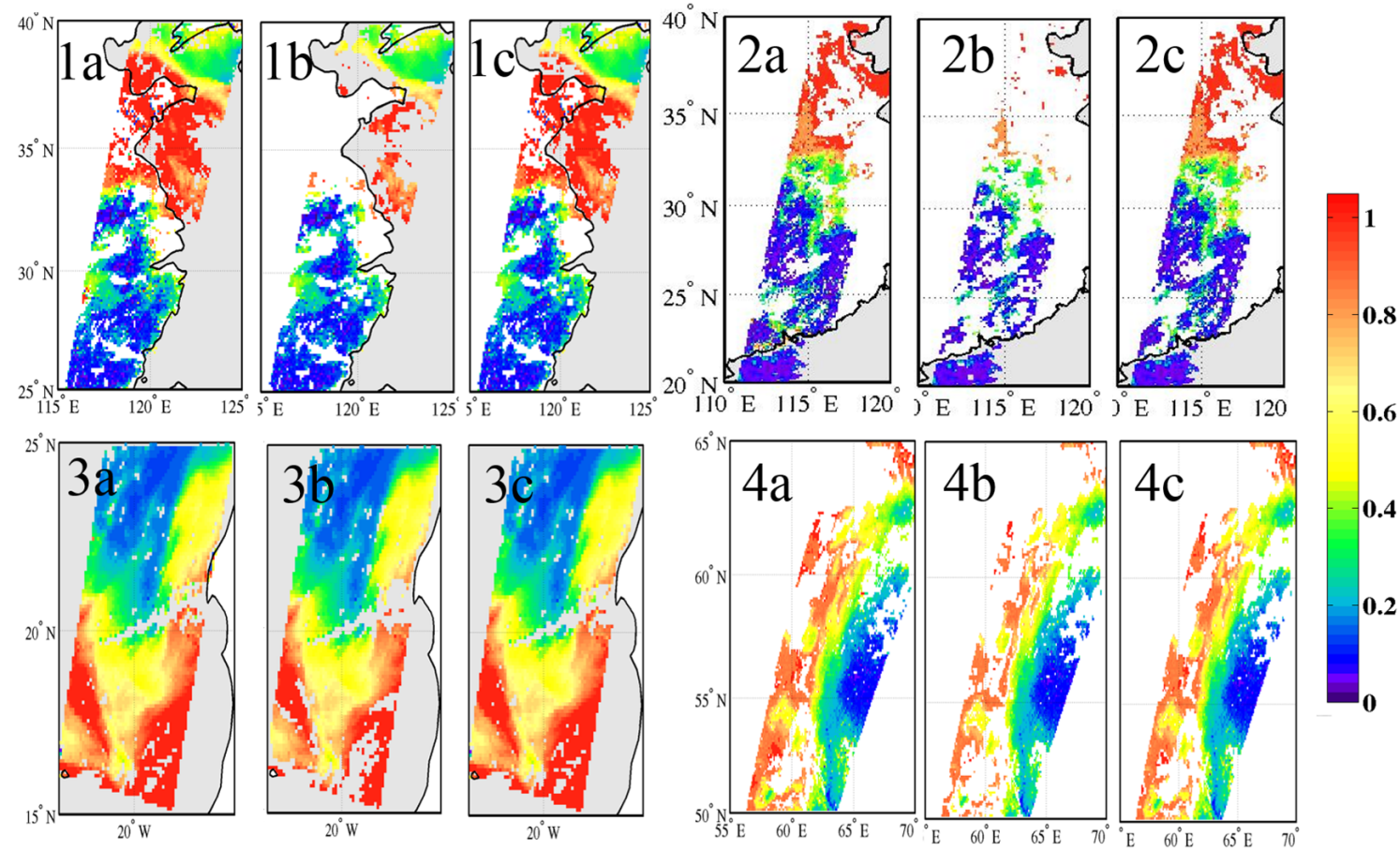

Figure 8. Example of retrieval scenes with high AOD. Upper row: over China on 3 August 2010 (case 1) and 24 July 2010 (case 2), lower row: Saharan dust outbreak on 12 March 2006 (case 3) and Siberian biomass burning episode on 1 August 2010 (case 4). For each of these cases we show (a) AOD retrieved with ADV/ASV, (b) AOD after application of the existing CPP and (c) AOD after application of the improved CPP. For orbit details, see Table 1.

where $<40 \%$ of the pixels retrieved are low-AOD $(<0.6)$ pixels (or, in other words, $>60 \%$ of the pixels retrieved are high-AOD ( $>0.6)$ pixels). For high-AOD regions, no postprocessing is applied; i.e. all pixels for which ADV/ASV provides AOD results are retained.

For the example over China (Figs. 4, 5a), the cumulative AOD distribution functions for each area are shown in Fig. 5b. Using the thresholds discussed above, the areas 1 and 2, which contained less than $40 \%$ of low $(<0.6)$ AOD pixels ( 23 and $34 \%$ respectively) were therefore classified as high-AOD areas for which all ADV/ASV-retrieved pixels are accepted. Hence, the high-AOD values are all retained. The areas 3 and 4 are classified as low-AOD regions, and Npix and AODstd tests are applied. The results of the application of the ExCPP (with standard deviation 0.1) versus the ImCPP tests (including the increased standard deviation to 0.2 , see AODstd threshold correction in Sect. 3.2.2) are illustrated in Fig. 3 for an area over Europe with a relatively low AOD and in Fig. 4 for an area with a high AOD over China. Over Europe (Fig. 3), the high-AOD region detection gave negative results (not detected). However, the improved CPP results in an increase of valid pixels as a result of the higher AODstd threshold. With ImCPP (Fig. 3c), more pixels are retained over the $\mathrm{UK}\left(\sim 53^{\circ} \mathrm{N}, 01^{\circ} \mathrm{W}\right)$ and western France, compared with ExCPP results (Fig. 3b). Over China (Fig. 4), a similar result was observed with ExCPP and ImCPP over the southernmost part of the track, while at the same time the high-AOD area was retained with ImCPP.

The effectiveness of the improved CPP method depends on the threshold set in the procedure to detect high-AOD regions. The thresholds used above (0.6 AOD, $40 \%$ of pixels) performed well in $95 \%$ of the cases. For the other $5 \%$ of the cases, mostly for small (less than $1000 \mathrm{~km}^{2}$ ) high-AOD regions and also for cases when less than $10 \%$ of pixels were retrieved with ADV/ASV, this default threshold did not provide acceptable results; e.g. high-AOD regions were not detected. Hence, for individual case studies the thresholds may have to be adjusted.

\subsubsection{ExCPP threshold correction}

As was discussed in Sect. 5.1, the implementation of the thresholds for the number of pixels (Npix) and AOD standard deviation (AODstd) in $3 \times 3$ pixels areas (Sect. 3.1) allows possible cloud contamination to be recognised and discarded in the presence of residual clouds and near cloud edges. However, further analysis showed that the thresholds chosen in ExCPP (Npix > 3, AODstd <0.1) are too strict in some cases and therefore some valid aerosol pixels near cloud edges are discarded. To avoid aerosol misclassification as clouds, the thresholds for Npix and AODstd were revised to allow for better coverage while retaining removal of cloud contamination, thus fulfilling the main requirements for the AOD data 


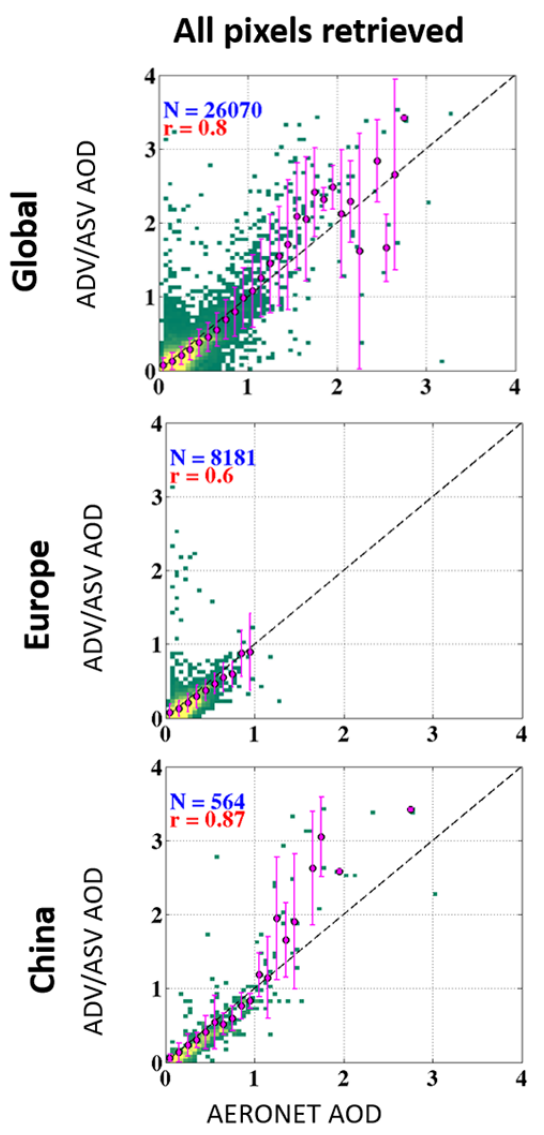

\section{Pixels left after ExCPP}
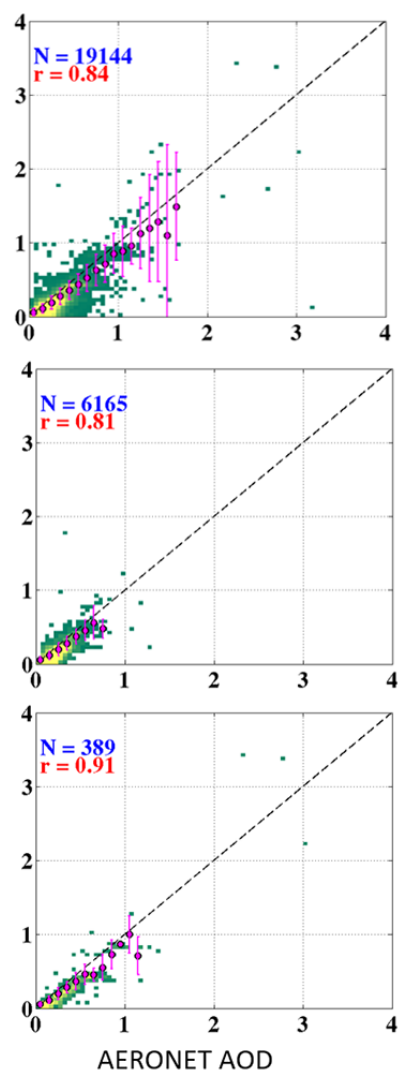

Pixels left after ImCPP
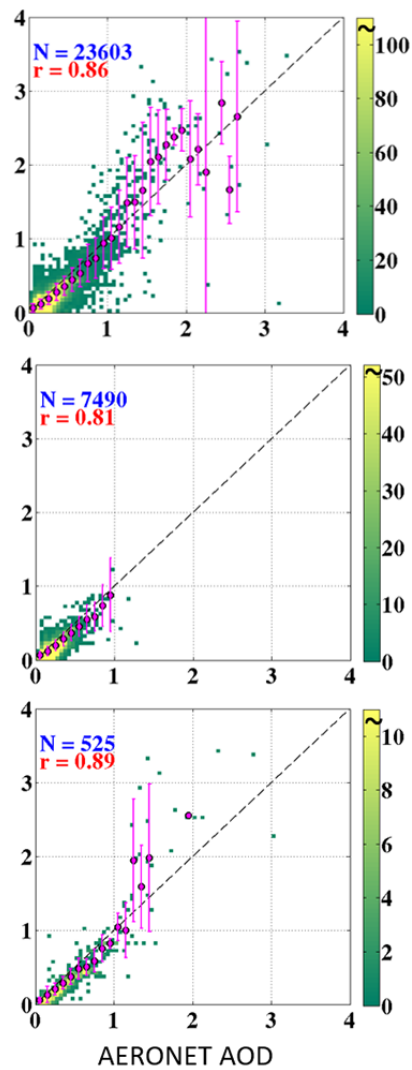

Figure 9. Scatter plots of AOD retrieved with ADV vs. AERONET AOD for all pixels retrieved (left column), for pixels left after application of the existing CPP (ExCPP, middle column) and for pixels left after applying the improved CPP (ImCPP, right column) for the whole world (upper row), Europe (middle row) and eastern China (lower row) for the period of 2002-2012. The black broken line is the identity line; $N$ is the number of pixels accepted for validation, $r$ is the correlation coefficient, magenta dots show ADV-retrieved AOD averaged to the bins, magenta lines show ADV/ASV AOD standard deviation in each bin; colour bar shows the number of ADV/AERONET data points.

sets - a good quality. We applied different combinations of thresholds to 1 year (2010) of ADV/ASV AOD data to study the sensitivity of the L2 (looking at the coverage and validation results) and L3 products (looking at the AOD mean value) using AERONET AOD for evaluation. The use of a subset, rather than a complete data record, is a common procedure in algorithm experiments (Holzer-Popp et al., 2013). In addition to the statistical methods applied, the visual inspection of the ADV/ASV-retrieved AOD fields has been carried out. We considered the visual inspection as additional to the statistics and a very important tool to check AOD over the areas where the AOD validation was not possible (e.g. near cloud edges where AERONET data are often cloud-screened or over regions where AERONET data are not available). The visual inspection of the AOD spatial distribution with different combinations of Npix and AODstd has been conducted over different aerosol loading areas randomly selected during the period 2007-2011.

We examined the Npix and AODstd thresholds combination that gives the optimum combination of AOD validation results and coverage. The ADV/AERONET AOD correlation coefficient and the percentage of pixels accepted from the number of all pixels retrieved with ADV/ASV were plotted together with the resulted AOD yearly mean values obtained with ExCPP (dashed line) and ImCPP (solid line) for various Npix and AODstd combinations (Fig. 6). Global results are presented in Fig. $6 \mathrm{a}$ and those over China in Fig. $6 \mathrm{~b}$. The results clearly show the effect of retaining high-AOD regions on both the coverage and the AOD values. With the AODstd $=0.1$ (as in ExCPP), about $15 \%$ of the retrieved pixels globally and more than $20 \%$ over high-AOD regions in China (as an example) are discarded from the ADV/ASV results as possibly cloud contaminated. When the test for recognising high-AOD regions is applied, ca. $2 \%$ pixels are accepted globally (ca. $5 \%$ over China) and the ADV AOD correlation with AERONET AOD increases (from 0.74 to 0.81 , globally). Since more high-AOD pixels are accepted now, the AOD mean value increases (from 0.129 to 0.138 ).

The results in Fig. 6 show that the value of AODstd is a more selective threshold than that of Npix. Keeping Npix at 3 

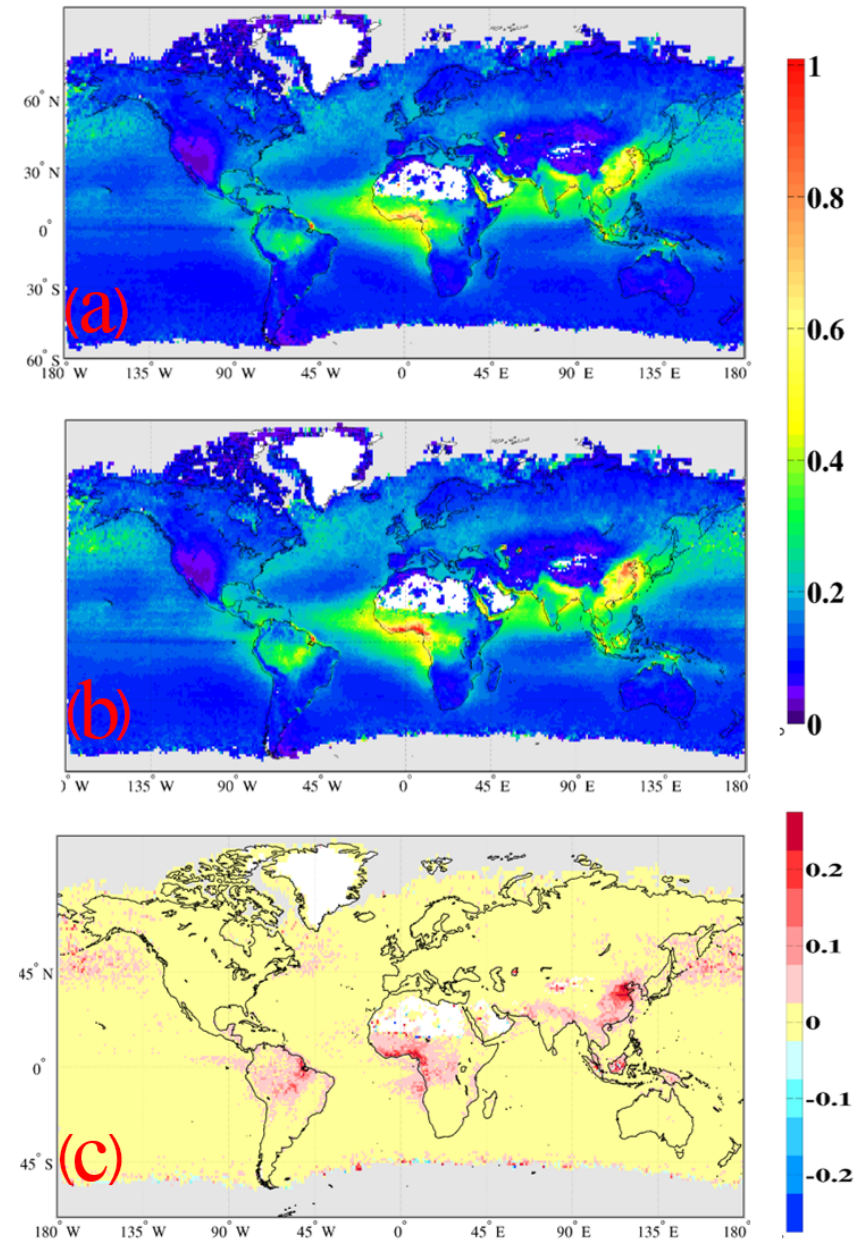

Figure 10. Global aggregated AOD retrieved with ADV/ASV for the period 2003-2011 after application of the ExCPP (a) or the ImCPP (b) and difference in AOD (c, AOD(ImCPP)-AOD(ExCPP)), as a result of the application of the ExCPP and ImCPP schemes.

(see below), the increase of the AODstd threshold from 0.1 to 0.2 results in an increase in the AOD coverage (ca. $5 \%$ more pixels are accepted globally and ca. $10 \%$ over China) with similar validation results. The number of validation points (not shown here) does not increase much, since AERONET measurements are performed for clear sky conditions and AOD testing near the cloud edges is not clearly seen in the validation results (note that validation was not possible over China with ExCPP, when high-AOD cases were discarded). A further increase of the AODstd threshold to 0.3 results in better coverage (3\% more pixels are accepted globally) with the same AOD validation results. However, visual inspection of the results from application of AODstd threshold values of 0.2 and 0.3 to the western European test case (Fig. 7) shows that with AODstd $<0.2$ most of the cloud-contaminated pixels are rejected (Fig. 7a), whereas with AODstd $<0.3$ cloudcontaminated pixels are accepted in the northern edge of the AOD pattern over the North Sea, eastern England and central
Europe (Fig. 7b). Therefore, the AODstd threshold of 0.2 was selected as an optimum.

A decrease of Npix from three to two, which potentially gives better coverage, has not been admitted, since it resulted in accepting more cloud contaminated pixels near the cloud edges (visual inspection, not shown here). Hence, for ImCPP, the ExCPP Npix threshold (Npix > 3) was retained. In summary, taking into account three main criteria, such as validation results, coverage and visual inspection, the combination of Npix $>3$ and AODstd $<0.2$ thresholds have been chosen for cloud contamination detection in low-AOD conditions globally.

\section{Results}

\subsection{Test cases}

To demonstrate how the ImCPP performs in different environments, we show (a) the AOD retrieved with ADV/ASV and AOD after post-processing using (b) the existing and (c) improved CPP schemes in Fig. 8 for anthropogenic emissions (case 1 and 2), Saharan dust outbreaks (case 3) and biomass burning in Russia (case 4). For the orbit details, see Table 1. Figure $8(3 \mathrm{a}-\mathrm{b}, 4 \mathrm{a}-\mathrm{b})$ shows that in most of the cases the ADV/ASV cloud detection tests (see Sect. 4) do not screen the high-AOD areas. However, many areas with high AOD were removed by the ExCPP (Figs. 8, 1a-b, 2a-b, Table 1). For the anthropogenic pollution cases, the number of the pixels left after the ExCPP, compared to those originally retrieved with ADV/ASV, was 71.6 and $55.8 \%$ for the cases 1 and 2 respectively (Figs. $8,1 \mathrm{~b}$ and $2 \mathrm{~b}$ ). As discussed more extensively for the test cases in Figs. 3 and 4, the ExCPP removes most of the high-AOD areas. After the application of the ImCPP the AOD coverage is considerably higher with 93.4 and $89.5 \%$ for the anthropogenic pollution cases (Figs. $8,1 \mathrm{c}$ and $2 \mathrm{c}$ ) as well as for the dust $(82.3 \%$, Figs. $8,3 \mathrm{c})$ and the biomass burning $(96.1 \%$, Figs. $8,4 \mathrm{c})$ events. Thus, the high-AOD area detection (Sect. 4.2) followed by CPP for the low-AOD areas effectively removes cloud-contaminated areas.

\subsection{Evaluation}

The effect of post-processing on the resulting AOD was evaluated by comparison with independent reference values available from ground-based sun photometer measurements from AERONET (Holben et al., 1998). The AERONET sun photometers, deployed at several hundred locations globally, measure solar irradiance at multiple wavelengths to provide AOD with an uncertainty of 0.01-0.02 (Eck et al., 1999). The cloud-screening algorithm developed for the AERONET has been comprehensively tested on experimental data obtained in different geographical and optical conditions (Smirnov et al., 2000). AERONET (quality assured) Level 2.0 AOD has been used for the ADV/ASV AOD validation, despite the fact 
Multi-annual means, 2003-2011
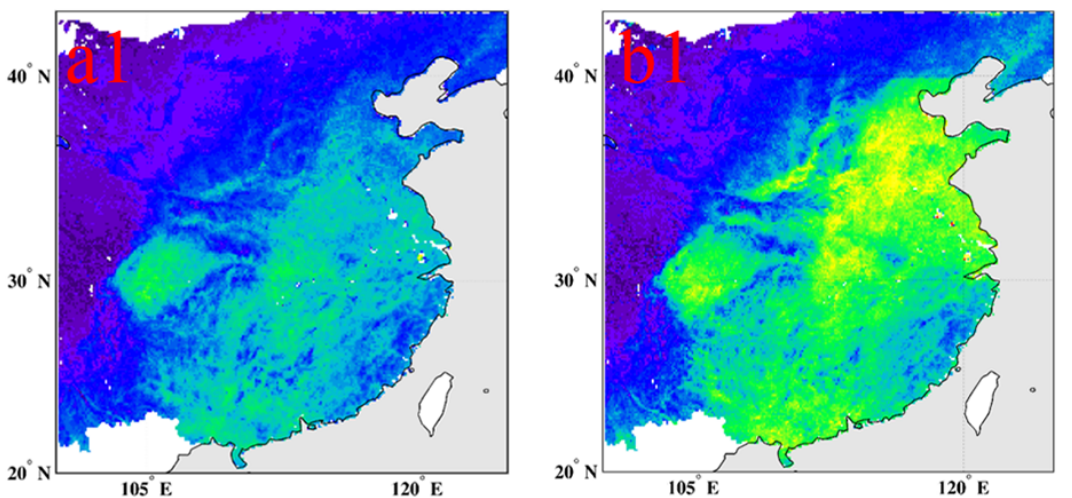

\section{5}

Seasonal means, 2003-2011

Winter
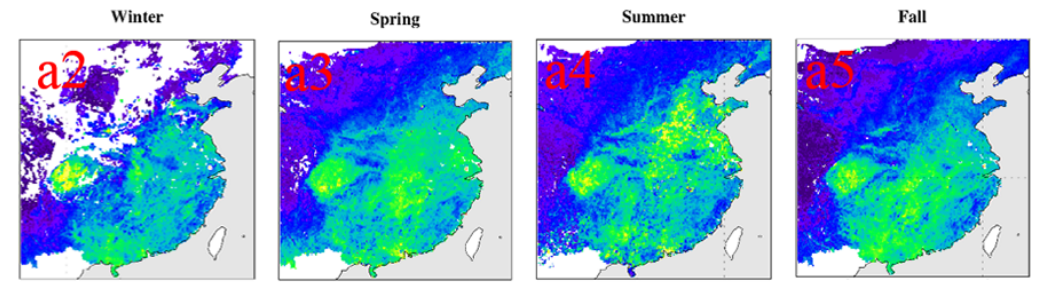

0.5
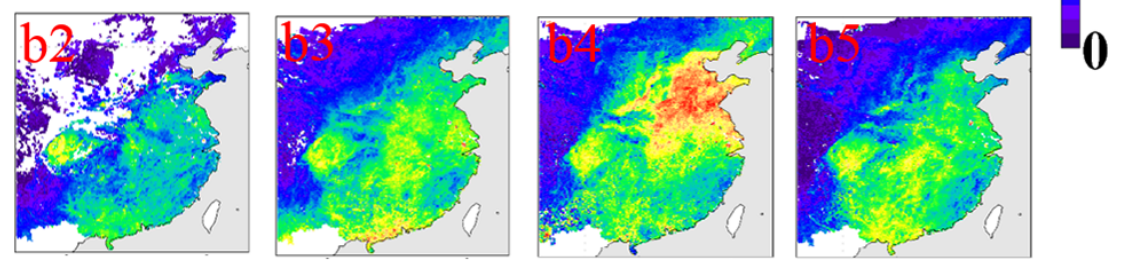

Figure 11. AOD over China for the period 2003-2011 retrieved using ADV and after application of the ExCPP (a) and the ImCPP (b) aggregated over the whole year (1) and seasonally (2-5, winter (DJF), spring (MAM), summer (JJA) and fall (SON) respectively).

that this algorithm (Smirnov et al., 2000) could have screened some high-AOD events.

Comparisons of the ADV/ASV-retrieved AOD and AOD results after application of either ExCPP or ImCPP with AERONET Level 2 AOD for the period 2002-2012 are shown in Fig. 9 globally, over Europe and over China. For each case, we report numbers of collocated ADV/AERONET pairs used in the validation $(N$, in blue) and the correlation coefficient $(r$, in red).

CPP has "cleaned" ADV/ASV AOD in two ways. Pixels with high ADV/ASV-retrieved AOD which could be cloud contaminated have been removed. However, as explained above, the ExCPP also inadvertently removes part of the "good" high-AOD pixels. With the ImCPP, which is less strict, about 15-20\% more pixels (from 73 to $91 \%$ globally, from 75 to $92 \%$ for Europe and from 69 to $93 \%$ for eastern China) have been accepted for validation as cloud-free pixels. Here, the ImCPP shows slightly better values compared to the ExCPP, correlation with the AERONET AOD globally (0.86 vs. 0.84$)$ and slightly worse correlation for China (0.89 vs. 0.91), while the correlation is similar (0.81) for Europe with both CPP schemes. Thus, with the ImCPP scheme we obtain better AOD coverage with better global quality.

The binned AOD mean and standard deviation are also indicated in Fig. 9. The bin approach clearly shows in which AOD range the retrieval results are in good agreement with the reference AOD provided by the AERONET. The averaged magenta circles (Fig. 9) show a good agreement between the ADV-retrieved and AERONET AOD for AOD $<1$. For AOD $>1$, ADV AOD is biased (overestimation in the AOD range 1.5-2 globally, as example), which partly might be explained by the sparse observations. However, for most of the bins with AOD $>1$, the AOD error bar is within the standard deviations.

\subsection{AOD spatial distribution after cloud post-processing}

The improvement in the CPP (as the increase in AOD coverage) results in changes in the spatial and temporal distribution of AOD (Fig. 10). With the ImCPP, high-AOD episodes are recognised more often and thus are not screened out as cloud (compare Fig. 8b and c), contributing to the aver- 

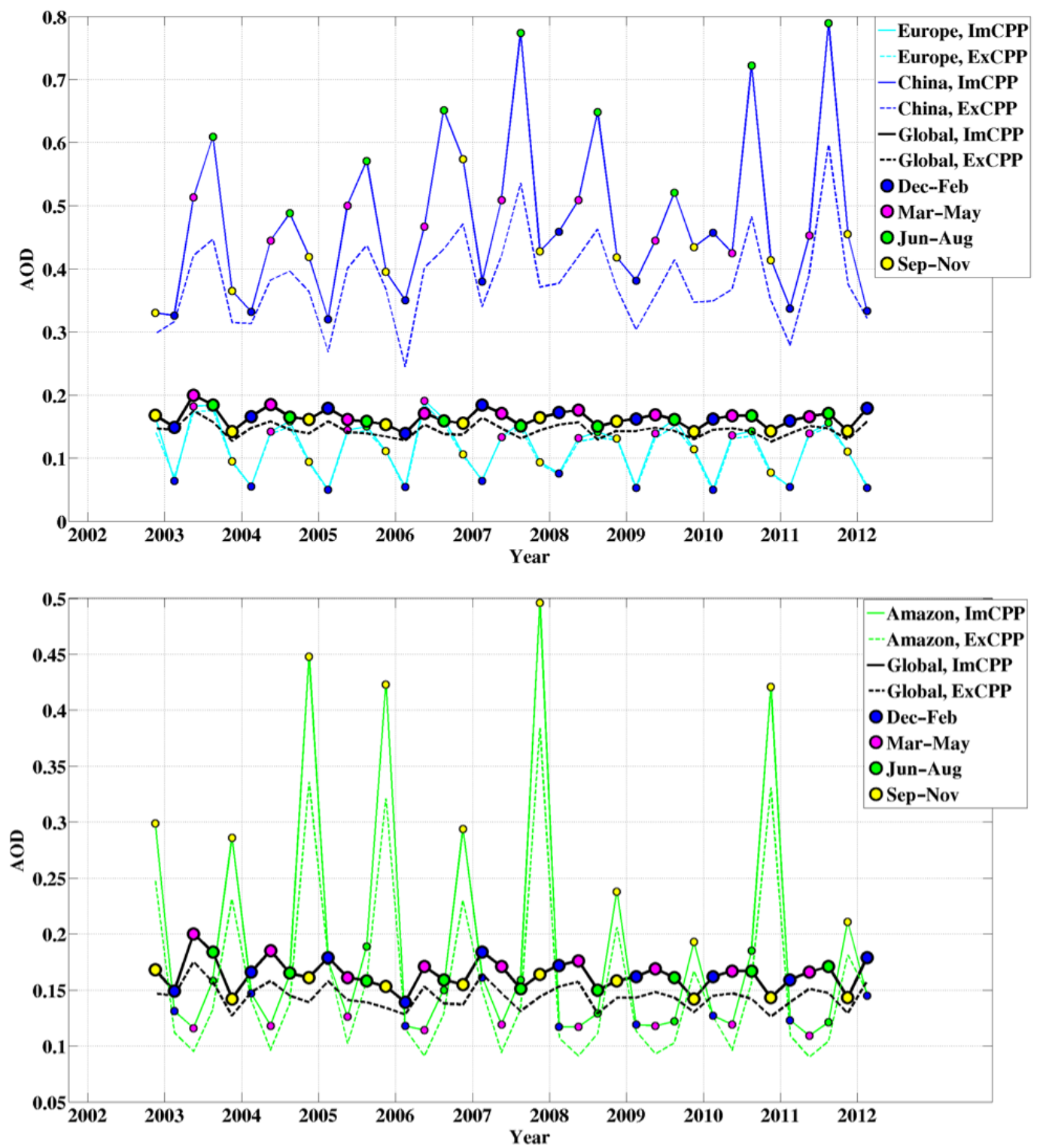

Figure 12. AATSR ADV AOD over land seasonal time series for the period 2002-2012 after application of the existing (dashed lines) and the improved CPP (solid lines) for different areas: Europe (light blue, upper panel), China (dark blue, upper panel) and Amazon (green, lower panel). Global AOD over land (black lines) is plotted on both panels, for comparison. Seasons are marked with coloured circles (see legend). Note the different AOD scales in each plot. For areas definition see Sect. 4.4.

aged AOD values. Over land, the yearly AOD value averaged over the whole period of 2003-2011 is higher by $\sim 13 \%$ (0.163 vs. 0.144$)$ with the improved CPP. Over ocean, the yearly AOD is higher by $\sim 8 \%$ (0.164 vs. 0.152$)$. The yearly global AOD value is higher by $\sim 9 \%$ ( 0.164 vs. 0.150$)$. The most visible increase in AOD is observed in high-AOD areas, such as over eastern China, over parts of India, during dust outbreaks over the Atlantic Ocean from the Sahara or over biomass burning areas in Africa and the Amazon (Fig. 10c). The seasonally averaged AOD values are higher by $0.010-0.018$; the exact values depend on the season be- cause the occurrence of high-AOD episodes are seasonal (e.g. for biomass burning).

As an example, the spatial distribution of the AOD over China for the period 2003-2011 yearly and for each season is presented in Fig. 11, as calculated with the ExCPP (Fig. 11a) and with the ImCPP (Fig. 11b). With the ImCPP, the multiannual mean AOD over China becomes 0.480 compared to 0.386 with the ExCPP. Seasonal changes in the AOD values after application of the two CPP methods are evident. The highest correction to the seasonal AOD over China occurs in the summer, when the mean AOD is 0.641, compared to the 
previous value of 0.467 (AOD value increase is 0.17 , or ca. $37 \%$ ). In the winter, when the AOD retrieval is limited by low solar zenith angle and snow on the ground, changes in AOD related to the ImCPP are not significant. Differences due to the improvements in CPP method are evident, especially for China, but the global values are also affected.

\subsection{AOD time series}

As discussed above, the ImCPP results in higher AOD values and obviously these are reflected in the time series. The seasonal AOD time series over land over different areas (Fig. 12) retrieved from the AATSR data using ADV have been presented and discussed in Kolmonen et al. (2016) where the ExCPP was applied. In the current section, we present the AATSR ADV AOD seasonal time series over land averaged globally, as well as over selected areas: polluted China $\left(25-40^{\circ} \mathrm{N}, 105-125^{\circ} \mathrm{E}\right)$, relatively clean Europe $\left(35-75^{\circ} \mathrm{N}\right.$, $\left.10^{\circ} \mathrm{W}-30^{\circ} \mathrm{E}\right)$ and biomass burning Amazon $\left(30^{\circ} \mathrm{S}-0^{\circ} \mathrm{N}\right.$, $35-85^{\circ} \mathrm{W}$ ) after the application of both the existing and the improved CPP schemes. Globally, the increase of AOD over land after ImCPP implementation was about 0.02 (Fig. 12). However, the contribution from the different regions to the globally averaged value was different.

In areas with relatively low AOD, such as Europe (Fig. 12a), which are not usually affected by high-AOD episodes, the difference between the seasonal AOD values calculated with the existing and the improved CPP is negligible. China (Fig. 11a) and India (not shown here), which are among the most polluted countries in Asia, contribute substantially to the higher AOD. In China, the application of the improved CPP results in an increase of the AOD value by 0.22 in the summer of 2006 , which is $51 \%$ of the value obtained with the existing CPP.

In other regions, the high-AOD episodes have seasonal behaviour. Thus, as a result of the application of the improved $\mathrm{CPP}$, a strong change in the AOD values is observed during the biomass burning seasons due to the retention of the highAOD events, as we expected. In the Amazon (Fig. 12b), the AOD values are higher by 30-40\% in September-November. In Africa (not shown here), an AOD increase by 20-30\% is observed in March-August. In India, during the monsoon season, the application of the ImCPP results in an increase of the AOD value by 0.26 in the summer of 2008 , which is $82 \%$ of the value obtained with the ExCPP.

\section{Conclusions}

The existing CPP scheme (Kolmonen et al., 2016) applied to AATSR-retrieved AOD using ADV/ASV resulted in the inadvertent loss of valid pixels, especially over areas with high AOD. Therefore, the scheme has been modified such that high-AOD areas are recognised and excluded from the post- processing. In addition, the post-processing selection criteria have been adjusted.

The main difference between the existing and improved CPP schemes is the increase in AOD coverage (globally, 10$15 \%$ more of the retrieved pixels are accepted with the ImCPP) and improved comparison with the AERONET AOD. This comparison shows that $91 \%$ of the ADV/ASV-retrieved points are accepted with the ImCPP, giving a better correlation coefficient $R=0.86$ (compared to $73 \%$ and 0.84 with the ExCPP) globally for AERONET validation for the period 2002-2012.

After the application of the ImCPP the AOD values for the period of 2003-2011 are higher by 0.019 with respect to the old scheme ( 0.163 vs. 0.144$)$ over land, by 0.012 (0.164 vs. $0.152)$ over ocean and by 0.014 (0.164 vs. 0.150$)$ globally. However, the strongest effect was on areas with a generally high AOD such as those with strong anthropogenic pollution and those affected by desert dust transport or biomass burning (e.g. China, India, Africa, South America). In the summer, the average AOD for the period 2003-2011 over China was higher by 0.174 (0.641 vs. 0.467$)$. Likewise, over India the summer 2008 AOD value increased by almost a factor of 2 (from 0.32 to 0.58 ).

While having a considerable improvement in both the AOD coverage and quality, the improved CPP method has its limitations related mostly to the threshold in high-AOD regions. The limiting value of more than $60 \%$ of pixels retrieved with AOD $>0.6$ has been chosen for the detection of high-AOD regions after examining ca. 150 high-AOD cases (ca. 500 tested areas) and this worked well in $95 \%$ of them. For the other $5 \%$ of the cases, mostly for small (less than $1000 \mathrm{~km}^{2}$ ) high-AOD areas and also for cases where less than $10 \%$ of the pixels were retrieved with ADV/ASV, this default threshold did not provide acceptable results; e.g. high-AOD areas were not detected. Thus, the ImCPP has been accepted as the default for global applications, but might be further improved when applied for AOD case studies over specific areas. The improved cloud post-processing method is applicable to other aerosol retrieval algorithms. However, the thresholds to detect the high-AOD regions, which were developed for AATSR, might have to be adjusted to the actual features of the instruments.

\section{Data availability}

AATSR ADV aerosol data are available on ICARE (http:// www.icare.univ-lille1.fr/, last access: 6 February 2017).

Competing interests. The authors declare that they have no conflict of interest. 
Acknowledgements. The research presented in this paper was carried out in the framework of the Marco Polo project (EU FP7 SPACE Grant agreement no. 606953), ESA-ESRIN project AO/16207/09/I-LG (Aerosol_cci), with further support by the Centre of Excellence in Atmospheric Science funded by the Finnish Academy of Sciences Excellence (project no. 272041).

We thank the editor Marloes Penning de Vries for her valuable comments and suggestions, which considerably improved the manuscript.

Edited by: M. Penning de Vries

Reviewed by: three anonymous referees

\section{References}

Baker, N.: VCM ATBD: VIIRS cloud mask algorithm theoretical basis document: 474-00033, available at: https://jointmission.gsfc.nasa.gov/sciencedocs/2015-06/

474-00044_Rev-Baseline.pdf (last access: 6 February 2017), 2013.

Birks, A.: ESA, VEGA Group PLC, and University of Leicester, AATSR Product Handbook, ESA, 2.2 Edn., available at: http://envisat.esa.int/handbooks/aatsr/CNTR.html (last access: 6 February 2017), 2007a.

Birks, A. R.: AATSR Technical Note: Improvements to the AATSR IPF relating to Land Surface Temperature Retrieval and Cloud Clearing over Land, Science and Technology Facilities Council, Rutherford Appleton Laboratory, 2007b.

Eck, T. F., Holben, B. N., Reid, J. S., Dubovik, O., Smirnov, A., O'Neill, N. T., Slutsker, I., and Kinne, S.: Wavelength dependence of the optical depth of biomass burning, urban, and desert dust aerosols, J. Geophys. Res., 104, 31333-31349, 1999.

Flowerdew R. J. and Haigh J. D.: An approximation to improve accuracy in the derivation of surface reflectance from multi-look satellite radiometers, Geophys. Res. Lett., 23, 1693-1696, 1995.

Grandey, B. S., Stier, P., and Wagner, T. M.: Investigating relationships between aerosol optical depth and cloud fraction using satellite, aerosol reanalysis and general circulation model data, Atmos. Chem. Phys., 13, 3177-3184, doi:10.5194/acp-13-31772013, 2013.

Frey, R. A., Acherman, S. A., Liu, Y., Strabala, K. I., Zhang, H., Key, J. R., and Wang, X.: Cloud detection with MODIS. Part I: Improvements in the MODIS cloud mask for Collection 5, J. Atmos. Ocean. Technol., 25, 1057-1072, 2008.

Holben, B. N., Eck, T. F., Slutsker, I., Tanré, D., Buis, J. P., Setzer,A., Vermote, E., Reagan, J. A., Kaufman, Y. J., Nakajima, T., Lavenu, F., Jankowiak, I., and Smirnov, A.: A ERONET- A Federated Instrument Network and Data Archive for Aerosol Characterization, Remote Sens. Environ., 66, 1-16, 1998.

Holzer-Popp, T., de Leeuw, G., Griesfeller, J., Martynenko, D., Klüser, L., Bevan, S., Davies, W., Ducos, F., Deuzé, J. L., Graigner, R. G., Heckel, A., von Hoyningen-Hüne, W., Kolmonen, P., Litvinov, P., North, P., Poulsen, C. A., Ramon, D., Siddans, R., Sogacheva, L., Tanre, D., Thomas, G. E., Vountas, M., Descloitres, J., Griesfeller, J., Kinne, S., Schulz, M., and Pinnock, S.: Aerosol retrieval experiments in the ESA Aerosol_cci project, Atmos. Meas. Tech., 6, 1919-1957, doi:10.5194/amt-61919-2013, 2013.
Kahn, R. A., Li, W.-H., Moroney, C., Diner, D. J., Martonchik, J. V., and Fishbein, E.: Aerosol source plume physical characteristics from space-based multiangle imaging, J. Geophys. Res., 112, D11205, doi:10.1029/2006JD007647, 2007.

Kaufman, Y. J., Remer, L. A., Tanre, D., Rong-Rong Li, Kleidman, R., Mattoo, S., Levy, R. C., Eck, T. F., Holben, B. N., Ichoku, C., and Koren, I.: A critical examination of the residual cloud contamination and diurnal sampling effects on MODIS estimates of aerosol over ocean, IEEE Geosci. Remote S., 43, 2886-2897, doi:10.1109/TGRS.2005.858430, 2005.

Koelemeijer, R. B. A., Stammes, P., Hovenier, J. W., and De Haan, J. D.: A fast method for retrieval of cloud parameters using oxygen A-band measurements from the Global Ozone Monitoring Instrument, J. Geophys. Res., 106, 475-3490, 2001.

Kolmonen, P., Sogacheva, L., Virtanen, T. H., de Leeuw, G., and Kulmala, M.: The ADV/ASV AATSR aerosol v2.30 retrieval algorithm: current status and presentation of a fullmission AOD data set, Int. J. Digital Earth, 9, 545-561, doi:10.1080/17538947.2015.1111450, 2016.

Martins, J. V., Tanré, D., Remer, L., Kaufman, Y., Mattoo, S., and Levy, R.: MODIS Cloud screening for remote sensing of aerosols over oceans using spatial variability, Geophys. Res. Lett., 29, doi:10.1029/2001GL013252, 2002.

Plummer, S: The GLOBCARBON Cloud Detection System for the Along-Track Scanning Radiometer (ATSR) Sensor Series, IEEE Geosci. Remote S., 46, 1718-1727, 2008.

Remer, L. A., Kaufman, Y. J., Tanre, D., Mattoo, S., Chu, D. A., Martins, J. V., Li, R. R., Ichoku, C., Levy, R. C., Kleidman, R. G., Eck, T. F., Vermote, E., and Holben, B. N.: The MODIS aerosol algorithm, products and validation, J. Atmos. Sci., 62, 947-973, 2005.

Roblez González, C.: Retrieval of aerosol properties using ATSR2 observations and their interpretation, $\mathrm{PhD}$ thesis, Universiteit Utrecht, 2003.

Shi, Y., Zhang, J., Reid, J. S., Liu, B., and Hyer, E. J.: Critical evaluation of cloud contamination in the MISR aerosol products using MODIS cloud mask products, Atmos. Meas. Tech., 7, 17911801, doi:10.5194/amt-7-1791-2014, 2014.

Smirnov, A., Holben, B. N., Eck, T. F., Dubovik, O., and Slutsker, I.: Cloud screening and quality control algorithms for the AERONET data base, Remote Sens. Environ., 73, 337-349, 2000.

Stap, F. A., Hasekamp, O. P., and Röckmann, T.: Sensitivity of PARASOL multi-angle photopolarimetric aerosol retrievals to cloud contamination, Atmos. Meas. Tech., 8, 1287-1301, doi:10.5194/amt-8-1287-2015, 2015.

Veefkind, J. P. and de Leeuw, G.: A new algorithm to determine the spectral aerosol optical depth from satellite radiometer measurements, J. Aerosol Sci., 29, 1237-1248, 1998.

Veefkind J. P., de Leeuw G., and Durkee P. A.: Retrieval of aerosol optical depth over land using two-angle view satellite radiometry during TARFOX, Geophys. Res. Lett., 25, 3135-3138, 1998.

Virtanen, T. H., Kolmonen, P., Rodríguez, E., Sogacheva, L., Sundström, A.-M., and de Leeuw, G.: Ash plume top height estimation using AATSR, Atmos. Meas. Tech., 7, 2437-2456, doi:10.5194/amt-7-2437-2014, 2014.

Wang, X., Li, W., Zhu, Y., and Zhao, B.: Improved cloud mask algorithm for FY-3A/VIRR data over the northwest region of China, 
Atmos. Meas. Tech., 6, 549-563, doi:10.5194/amt-6-549-2013, 2013.

Závody, A. M, Mutlow C. T., and Llewellyn-Jones, D. T.: Cloud Clearing over the Ocean in the Processing of Data from the Along-Track Scanning Radiometer (ATSR), J. Atmos. Ocean. Technol., 17, 595-615, 2000.

Zhao, T. X.-P., Chan, P. K., and Heidinger, A. K.: A global survey of the effect of cloud contamination on the aerosol optical thickness and its long-term trend derived from operational AVHRR satellite observations, Geophys. Res. Atmos., 118, 2849-2857, doi:10.1002/jgrd.50278, 2013.
Zhang, J., Reid, J. S., and Holben, B. N.: An analysis of potential cloud artifacts in MODIS over ocean aerosol optical thickness products, Geophys. Res. Lett., 32, L15803, doi:10.1029/2005GL023254, 2005. 